\title{
Contribuição da produção de biodiesel para a economia circular utilizando dinâmica de sistemas
}

\section{Emmanuelle Soares de Carvalho Freitas ${ }^{1}$, Lúcia Helena Xavier $^{2}$ e Lilian Lefol Nani Guarieiro ${ }^{3}$}

${ }^{1}$ Centro Universitário Senai Cimatec. Doutorado em Gestão e Tecnologia Industrial. Av. Orlando Gomes, 1845. Piatã. Salvador-BA, Brasil (CEP 41650-010). E-mail: emmanuelle-freitas@hotmail.com.

${ }^{2}$ Universidade Federal do Rio de Janeiro. Centro de Tecnologia Mineral. Av. Pedro Calmon, 900. Cidade Universitária. Rio de Janeiro-PB, Brasil (CEP 21941-908).

${ }^{3}$ Centro Universitário Senai Cimatec. Av. Orlando Gomes, 1845. Piatã. Salvador-BA, Brasil (CEP 41650-010).

Resumo. A necessidade em adequar os processos produtivos aos novos paradigmas da economia circular, transformando os resíduos em insumos produtivos, representa um grande desafio. A produção de fontes alternativas de energia a partir de matériaprima residual representa uma significativa contribuição dentro do conceito da economia circular. Desta forma, este trabalho utiliza a dinâmica de sistemas para o desenvolvimento de um modelo de simulação, analisando a integração do óleo residual na cadeia de produção e uso do biodiesel. 0 modelo analisado utilizou o software Vensim, avaliando três cenários em um período de 10 anos, verificando as possíveis mitigações de impacto em decorrência da correta destinação do óleo residual por meio da produção de biodiesel. Os resultados obtidos com a simulação dos cenários mostram que o cenário sustentável representa uma redução dos impactos ambientais que acontecem em função do descarte deste resíduo, redução nas emissões de $\mathrm{CO}_{2}$ e aumento na produção de biodiesel.

Palavras-chaves: Biodiesel; Óleo residual de fritura; Economia circular; Análise de cenários; Dinâmica de sistemas.

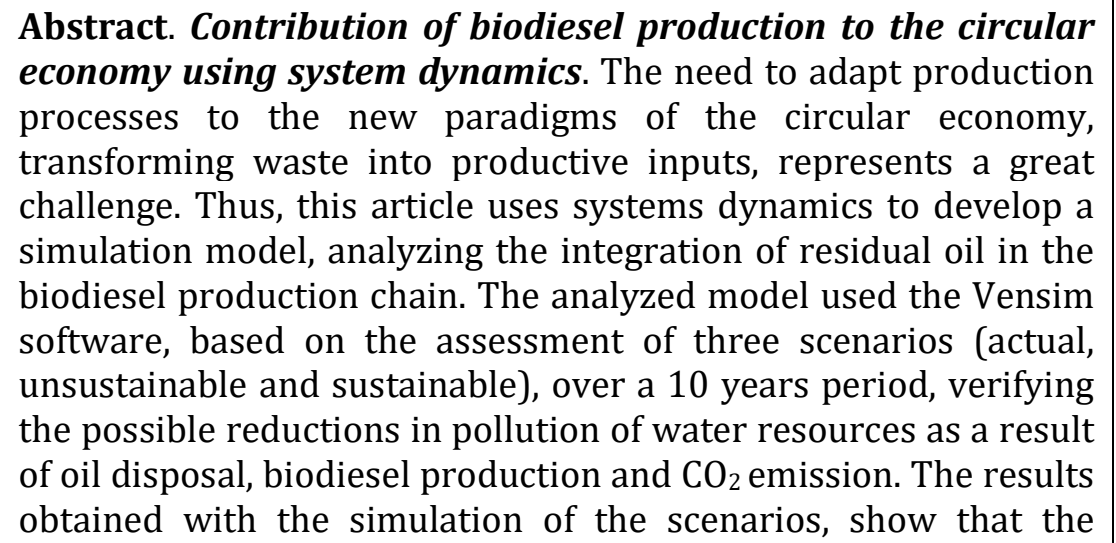

Recebido

$17 / 01 / 2021$

Aceito

$30 / 03 / 2021$

Disponível on line $04 / 04 / 2021$

Publicado $30 / 04 / 2021$

Acesso aberto

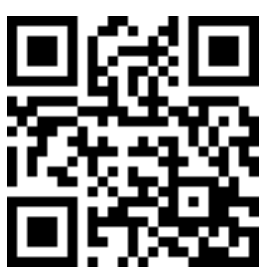

(D) 0000-0002-1466-6618 Emmanuelle Soares de Carvalho Freitas

(D) 0000-0003-4177-5251 Lúcia Helena Xavier

ISSN 2359-1412/RBGAS-2021-0003/2021/8/18/5/93

Rev. Bras. Gest. Amb. Sustent.

http://revista.ecogestaobrasil.net 
sustainable scenario represents a great reduction of the environmental impacts that happen due to the disposal of this waste, reduction in $\mathrm{CO}_{2}$ emissions and increase in the production of biodiesel.

Keywords: Biodiesel; Residual frying oil; Circular economy; Scenario analysis; System dynamics.
D $0000-0003-3950-3660$

Lilian Lefol Nani

Guarieiro

\section{Introdução}

A demanda de recursos naturais para suprir a demanda dos processos produtivos e logísticos tem superado a capacidade de reposição dos recursos renováveis, levando a necessidade de adoção de recursos alternativos. Nos últimos 50 anos, cerca de $60 \%$ do ecossistema da terrestres sofreram algum tipo de impacto e até 2030 o planeta terá três bilhões de novos consumidores, produzindo mais, consumindo mais e descartando seus resíduos (Weetman, 2019).

Assim, nos últimos anos, os esforços para desenvolver produtos e serviços mais sustentáveis e eficientes, com redução dos impactos ambientais, resultam em soluções pautadas em zerar o desperdício e ainda obter ganhos econômicos e ambientais. Neste contexto, é fundamental que haja uma transição de um modelo econômico tradicional (linear) que segue um determinado padrão produzir-usar-descartar (do inglês, produce-use-dispose) e que se baseia principalmente no uso de fontes não renováveis e finitas, com descarte de forma inapropriada, para uma economia circular que ultrapassa os conceitos relacionados apenas a gestão de resíduos e de reciclagem, pautada nas propostas de sistemas restaurativos e regenerativos para o desenvolvimento de produtos e serviços (EMF, 2013).

Desta forma, o alto consumo energético, o esgotamento dos combustíveis fósseis, as mudanças climáticas, a poluição gerada e o comprometimento da segurança energética, remetem à adoção de medidas que revertam este cenário por meio do desenvolvimento de soluções sustentáveis e viáveis na área da bioenergia, como o uso de fontes alternativas e renováveis.

A busca por fontes energéticas alternativas e renováveis, que possam substituir parcial ou total os combustíveis fósseis, resultou, entre outros aspectos, no desenvolvimento de biocombustíveis obtidos a partir de fontes renováveis, tais como soja, cana-de-açúcar, mamona, soja, canola, algas ou ainda de óleos e gorduras residuais (Ahmad et al., 2011; Atabani et al., 2012; Aversari et al., 2018). Os biocombustíveis estão fortemente relacionados com o conceito de sustentabilidade, a partir do qual o uso de recursos naturais para atender às necessidades não deve comprometer as necessidades das gerações futuras (Bizawu e Aguiar, 2016). Essa busca por fontes de energias renováveis ocorre pela preocupação com a finitude dos recursos naturais, principalmente com as reservas de petróleo, e pelo fim da petrodependência. Assim, a utilização de fontes energéticas renováveis passam a alcançar grande importância, tanto nas esferas ambientais, quanto pela necessidade de se conter o uso de combustíveis fósseis.

A maior parte dos insumos utilizados na produção de biocombustíveis são provenientes de culturas alimentares como soja, cana-de-açúcar, beterraba açucarada e semente oleaginosa, gerando um problema de segurança alimentar. Na medida em que terras que eram destinadas para a produção de alimentos agora são destinadas para a produção de biodiesel, já que muitos agricultores trocaram as culturas destinadas à alimentação humana por culturas destinadas à produção de biodiesel (Pauli et al., 2020). Outro fator, seria o aumento da produção de biodiesel que resultaria numa valorização do 
preço dos alimentos que foram usados na produção do biocombustível, em razão do comprometimento da oferta (Sorda et al., 2010).

No Brasil, a indústria de produção e o consumo de biodiesel tem crescido ao longo dos últimos anos e a participação desse combustível tem aumentado cada vez mais na matriz energética, tendo alcançado $12 \%$ de adição ao diesel com a implementação do B12 no primeiro semestre de 2020 (ANP, 2020). Em 2019, a produção de biodiesel atingiu a marca de quase 6 bilhões de litros, enquanto em 2018 a marca foi de 5.3 bilhões de litros (ABIOVE, 2020). Este crescimento provavelmente acontece devido à evolução tecnológica e da regulamentação nacional que incentiva o aumento do teor de biodiesel na mistura diesel/biodiesel, estimulando a adição e produção de biocombustíveis no cenário energético brasileiro, o que favorece, de certa forma, a inserção de novos insumos, que podem representar soluções, de forma equilibrada e sustentável, para a matriz energética nacional.

Atualmente, a soja é majoritariamente a principal matéria-prima para a produção de biodiesel com cerca de 70\% de participação (ANP, 2020). 0 Brasil é o segundo maior produtor de soja do mundo, ficando atrás apenas dos Estados Unidos (EMBRAPA, 2020). É importante ressaltar que devido à grande produção de soja no Brasil, o óleo de soja é o mais utilizado no processo de cocção dos alimentos, gerando um resíduo que possui grande potencial de oferta de insumo a partir do óleo residual.

O Brasil possui uma população com cerca de 210 milhões de habitantes e, de acordo da ABIOVE (2020), o país consome cerca de 2,1 bilhões de litros de óleo vegetal por ano, valor representativo para o principal modal de transporte brasileiro, o rodoviário. Além da utilização de culturas oleaginosas para a produção de biocombustível, há a possibilidade de uso de óleos e gorduras residuais (OGR) como óleo residual de fritura, por exemplo.

Admitindo-se que o óleo que foi utilizado no processo de fritura, tenha uma perda de $50 \%$ em seu volume devido a evaporação, desperdícios e absorção pelos alimentos, esse volume pode chegar a um total de 1 bilhão de litros de óleo residual, que em sua maioria é descartado de forma inadequada no meio ambiente (UBRABIO, 2020).

Em 2018 e 2019, percentuais de 1,76\% e 1,54\%, respectivamente, de todo óleo residual gerado no Brasil foi destinado para a produção de biodiesel. Em ambos os anos, mais de 1,5 milhão de litros foram descartados de forma incorreta no meio ambiente, impactando os serviços e infraestrutura de saneamento, bem como impactando cursos hídricos e ecossistemas. Assim, se todo o resíduo de óleo fosse reaproveitado na matriz energética nacional, poderia alavancar o volume de produção de biodiesel no Brasil, representando uma diminuição do atual consumo de diesel e um importante fomento à proposta da economia circular (ANP, 2020).

Embora o setor de biodiesel tenha sofrido com as turbulências da pandemia, no ano de 2020, o total de produção de biodiesel foi de 6.432.037.000 bilhões de litros no mercado, equivalendo a cerca de seis bilhões e meio de litros, dos quais 1,14\% é resultante do processamento de óleo residual de fritura, ou seja, mais de 73 milhões de litros (ABIOVE, 2020; ANP, 2020).

A conversão do óleo residual de fritura em biodiesel tem eficiência de $80 \%$, ou seja, para cada litro de óleo residual gera-se 0,8 litro de biodiesel (Barbosa e Pasqualetto, 2007). Utilizando-se desta conversão, para gerar 73.325.221,80 L de biodiesel, foi necessário o uso de 91.656.527,25 L de óleo de fritura, uma parte ínfima de todo o resíduo que é gerado anualmente pela população brasileira. Caso todo o resíduo de óleo de fritura consumido no país fosse utilizado para este fim, a produção nacional de biodiesel aumentaria em quase $24 \%$. Um aumento incremental na matriz energética.

0 uso de matérias-primas residuais para a produção de um biocombustível movimenta diferentes modelos de negócio sustentável desde a coleta e processamento do insumo até a produção, representando um conjunto de boas práticas industriais no 
segmento produtivo de biodiesel, podendo ser uma solução desejável no âmbito da economia circular na esfera mais ampla da gestão ambiental. Desta forma, a produção de biodiesel utilizando óleos residuais contribuem para mitigar os efeitos negativos que o descarte inadequado deste resíduo pode trazer ao meio ambiente. Segundo a ECOLEO (2015) apenas um litro de óleo é capaz de contaminar até 20 mil litros de água potável. 0 óleo residual em contato com a água compromete as trocas gasosas com o meio aquático, resultando em um processo de eutrofização, que é um processo em que ocorre um aumento na concentração de nutrientes, principalmente fósforo e nitrogênio, ocasionando o aumento de algas, cianobactérias e bactérias aeróbias (Pereira et al., 2013).

Desta maneira, o crescente incentivo às atividades para o reaproveitamento e circularidade de insumos residuais, pode significar uma mudança na forma de gerenciar os recursos, recuperando e agregando valor para produtos em fim de uso e possibilitando a reinserção em novas cadeias produtivas.

Assim, torna-se evidente a importância da utilização de um novo modelo econômico pautado na economia circular (EC), que faz uso de tecnologias baseadas na reinserção dos resíduos e produtos pós-consumo na cadeia produtiva, visando a ampliar as oportunidades e perspectivas na cadeia de produção de biodiesel, permitindo que o resíduo de um processo se torne matéria-prima de outro, maximizando o aproveitamento de recursos (Oliveira e Gonçalves, 2016).

0 reaproveitamento de uma matéria-prima residual é um aspecto que reforça a importância econômica da circularidade dos produtos, para manter o processo de fluxo de materiais e produtos em sua maior utilidade, transformando um resíduo em um novo recurso. Embora o óleo residual de fritura ainda tenha uma participação incipiente na produção de biodiesel, são grandes as motivações para o uso desta matéria-prima, desde a disponibilidade de oferta ao custo reduzido por se tratar de um insumo residual. A ressignificação deste insumo representa um aumento da participação do óleo residual de fritura na matriz energética nacional.

Neste contexto, este trabalho teve como objetivo avaliar a contribuição da produção de biodiesel para a economia circular. Para tanto foi utilizada a dinâmica de sistemas, por meio do software VENSIM PLE, para o desenvolvimento de um modelo matemático, que apresenta uma avaliação sobre o aproveitamento de uma matéria-prima residual, utilizando a análise de três cenários (atual, sustentável e não sustentável).

\section{Metodologia}

0 desenvolvimento desta pesquisa foi pautado na necessidade de se evidenciar o desempenho do uso de óleo residual de fritura (ORF) como insumo produtivo na cadeia do biodiesel. Para tanto, baseou-se na metodologia de dinâmica de sistemas e análise de cenários sustentável e não sustentável em comparação ao cenário atual. Estes cenários estão relacionados com a participação do óleo residual de fritura no processo de produção do biodiesel, em um período de 10 anos (2020 a 2030). Para isto, foi necessário identificar algumas variáveis, a partir seguintes das seguintes etapas, (1) estudo exploratório elaborado a partir de relatórios, dados estatísticos relevantes, utilizando como fontes de informações dados da (ABIOVE, 2020; APROBIO, 2020; UBRABIO, 2020), que juntas representam $90 \%$ de todo o biodiesel nacional e esses dados serviram para validação do modelo que foi desenvolvido; (2) construção de um modelo que represente a situação a ser estudada, utilizando o software VESIM PLE para representar o problema (Figura 1); (3) análise dos cenários obtidos; e (4) identificação do melhor cenário a partir das informações anteriores.

O cenário brasileiro atual consiste em um combustível composto por $12 \%$ de biodiesel e 88\% de diesel (B12). Quanto à matéria-prima secundária, apenas de $2 \%$ do óleo de fritura residual é reciclado e o descarte representa $98 \%$ do total pós-consumo. Do 
percentual reciclado, $0,46 \%$ são dedicados à produção de sabão, verniz, resina entre outros e, uma ínfima parte $(1,54 \%)$ vai para a produção de biodiesel (ABIOVE, 2020; UBRABIO, 2020). 0 cenário pessimista, denominado NS (não sustentável) foi estruturado na possibilidade do surgimento de gargalos, como a inserção de novas matérias-primas, implicando em uma menor participação do óleo residual de fritura na cadeia de produção do biodiesel. Enquanto o cenário otimista SUS (sustentável) apresenta o oposto, uma maior participação do óleo residual de fritura na produção de biodiesel, alavancando a produção deste biocombustível no país e aumentando o percentual de adição ao diesel.

O objetivo do desenvolvimento do modelo é apresentar graficamente a dinâmica entre as variáveis, explicando as relações diretas e indiretas entre as variáveis e suas diversas interpretações. Sendo assim, em relação ao conteúdo do modelo construído, foi apresentado todas as possíveis variáveis do tipo nível, do tipo taxa e as variáveis auxiliares, além das relações entre elas, a partir da problemática sobre a utilização do óleo residual para produção de biodiesel. $\mathrm{Na}$ análise dos diagramas de fluxo é possível perceber as estruturas causais, com elos de inter-relação. Esses elos dão-se quando diminuímos o volume de óleo descartado, diretamente estaremos diminuindo a taxa de descarte e poluição do meio ambiente (água), com isso, diminuiria a poluição do meio ambiente (água), aumentando assim o volume de óleo destinado à reciclagem.

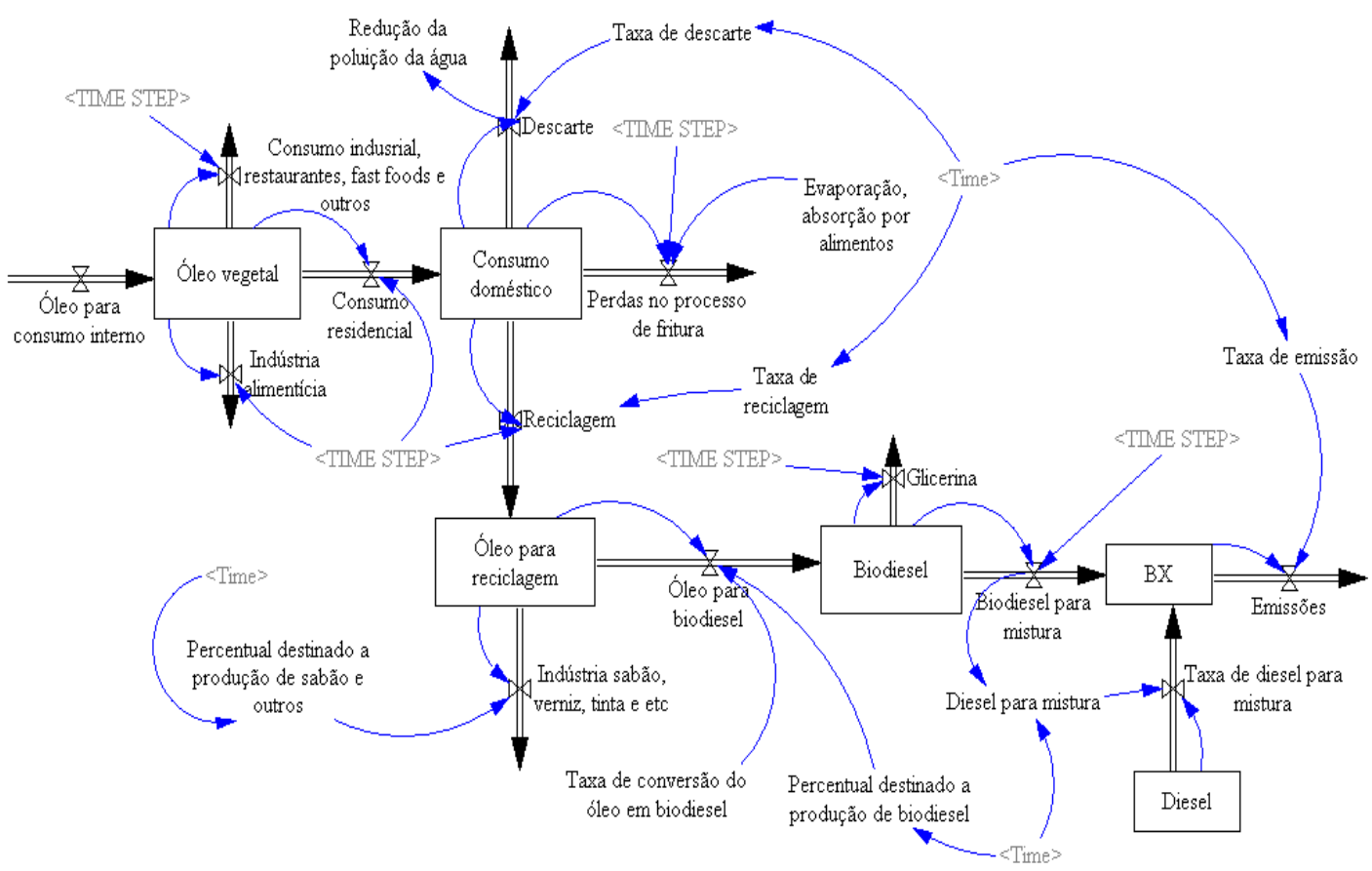

Figura 1. Modelo de análise desenvolvido. Fonte: Elaboração própria utilizando o software Vensin PLE.

\section{Modelagem dos dados}

Em relação ao modelo desenvolvido e às variáveis propostas, estas fornecem diversas explicações e são utilizadas para analisar a relação entre elas, cujos valores determinam o melhor aproveitamento desse resíduo e o destino para a produção do 
biodiesel. Para isto, o modelo integra diversas variáveis relevantes para o este estudo como:

(1) 0 óleo vegetal, que tem como estoque (entrada), a variável óleo para consumo interno e possui três fluxos de saída: (i) para a variável indústria alimentícia $(1,8$ bilhão de litros de óleo), que vai para a produção de maionese, gorduras e preparações alimentícias; (ii) para a variável consumo por indústrias, restaurantes e fast foods, que é cerca 3,9 bilhões de litros; e (iii) para a variável consumo doméstico que é cerca de 2,1 bilhões de litros (ABIOVE, 2020);

(2) 0 consumo doméstico de óleo possui três fluxos de saída: (i) o óleo que vai para descarte; (ii) perdas no processo de fritura, por evaporação ou absorção pelos alimentos, que pode chegar a 50\% de perda neste processo de cocção; e (iii) o óleo disponível para reciclagem;

(3) 0 descarte foi determinado a partir dos valores atuais de descarte do óleo a partir do consumo doméstico (2,1 bilhões de litros) e a variável taxa de descarte (98\%). A variável taxa de descarte foi influenciada pela variável TIME, que indica a unidade de tempo durante a execução do modelo, neste caso, um período de 10 anos (2020-2030). Esta variável também foi determinada pelos cenários que foram estudados, aumentando e diminuindo a taxa conforme as informações do cenário que estava sendo simulado;

(4) Para poluição da água, cujo resultado é obtido através produto da variável descarte pelo potencial poluidor deste resíduo, foi utilizado definido que para cada litro de óleo descartado 20.000 litros de água foi contaminado (UBRABIO, 2020);

(5) A variável óleo para reciclagem depende dos valores obtidos a partir das variáveis taxa de reciclagem (onde também foi utilizada a variável TIME) e a quantidade de óleo disponível para a reciclagem (2\%) que foi sendo alterado conforme o cenário simulado (UBRABIO, 2020). Dois fluxos de saída foram definidos: (i) o que vai para o segmento de sabão, vernizes e outras indústrias, que é determinada pela variável percentual destinado a indústria de sabão etc, esta também é influenciada pela variável TIME, modificada de acordo com o cenário simulado; e (ii) para a variável óleo para biodiesel, que tem outras duas variáveis determinantes, a variável taxa de conversão, onde foi utilizado o valor de $80 \%$ (Santos, 2009), e a variável percentual destinado ao biodiesel, que também utilizada a variável TIME.

(6) A variável biodiesel é o resultado do óleo para biodiesel. Desses, 90\% vai para o biodiesel, e os outros $10 \%$ são transformados em glicerina. Esta variável tem como fluxo de saída o biodiesel para mistura, que é determinada pela variável biodiesel e pela variável TIME STEP, que é uma variável que indica a quantidade de ciclos de cálculo em cada unidade de tempo.

(7) A variável BX, é determinada pelo somatório da quantidade de biodiesel para mistura, taxa de diesel para mistura menos as emissões. A taxa de diesel é definida pela variável diesel para mistura, que é influenciada pela variável TIME e pelo diesel disponível (ANP, 2020).

(8) A variável emissões é definida pela multiplicação da variável BX e pela variável taxa de emissão, que também é determinada pela variável TIME. As taxas de emissões foram definidas de acordo com as emissões de Gases de Efeito Estufa 2050: Implicações Econômicas e Sociais do Cenário de Plano Governamental (D’Agosto, 2016).

A partir destes dados, foram definidas as equações que foram utilizadas no modelo simulado. Todas as equações estão descritas na Tabela 1. 
Tabela 1. Parâmetros utilizados na modelagem dos dados.

\begin{tabular}{|c|c|}
\hline Variável & Parâmetros \\
\hline Óleo para consumo interno (L) & 7,8 bilhões de litros \\
\hline Óleo vegetal (L) & $\begin{array}{l}\text { Óleo para consumo interno (L)- "Consumo } \\
\text { indusrial, restaurantes, fast foods e outros" (L)- } \\
\text { Consumo residencial (L)-Indústria alimentícia(L) }\end{array}$ \\
\hline Indústria alimentícia (L) & Óleo vegetal (L)*0.2307/time step \\
\hline Consumo industrial (L) & Óleo vegetal(L)*0,5/time step \\
\hline Consumo residencial (L) & Óleo vegetal (L)*0,2692/time step \\
\hline Consumo doméstico (L) & $\begin{array}{l}\text { Consumo residencial (L) - Descarte (L) - Perdas } \\
\text { no processo de fritura (L) - Reciclagem(L) }\end{array}$ \\
\hline Descarte (L) & Taxa de descarte $*$ Consumo doméstico (L) \\
\hline Taxa de descarte (\%) & 98\% usando a variável time \\
\hline Poluição de água (L) & Descarte (L)*20.000 \\
\hline Reciclagem (L) & $\begin{array}{c}\text { Taxa de reciclagem * Consumo doméstico/time } \\
\text { step }\end{array}$ \\
\hline Taxa de reciclagem (\%) & $2 \%$ usando a variável time \\
\hline Óleo para reciclagem (L) & $\begin{array}{l}\text { Reciclagem (L) -"Indústria sabão, verniz, tinta e } \\
\text { etc" (L) - Óleo para biodiesel (L) }\end{array}$ \\
\hline Biodiesel (L) & $\begin{array}{c}\text { Óleo para biodiesel (L) - Biodiesel para mistura } \\
(\mathrm{L}) \text { - Glicerina(L) }\end{array}$ \\
\hline Biodiesel para mistura (L) & $\mathrm{V}_{\mathrm{B} 100} * 0.9 /$ time step \\
\hline Glicerina (L) & Biodiesel $(\mathrm{L}) * 0,1 /$ time step \\
\hline $\mathrm{BX}(\mathrm{L})$ & $\begin{array}{c}\text { Biodiesel para mistura (L) + Taxa de diesel para } \\
\text { mistura - Emissões (L) }\end{array}$ \\
\hline Emissões (L) & BX $(\mathrm{L}) *$ Taxa de emissão \\
\hline Taxa de emissão & Time (de acordo com o cenário simulado) \\
\hline
\end{tabular}

Onde: $\mathrm{V}_{\mathrm{B} 100}=$ volume em Litros de biodiesel puro;

$0,2307=1,8$ bilhões do total de óleo para consumo interno destinado a indústria alimentícia;

$0,2692=2,1$ bilhões do total de óleo para consumo interno destinado para o consumo residencial;

$0,5=3,9$ bilhões do total de óleo para consumo interno destinado para o consumo industrial;

$0,9=90 \%$ da produção de biodiesel;

$0,1=10 \%$ de glicerina.

0 modelo desenvolvido proporciona diversas análises. Vale ressaltar que o modelo é aberto a novas configurações, onde novos dados podem ser inseridos, de acordo com a realidade do cenário que deseja ser simulado. A partir da modificação nos valores das taxas e variáveis, novos resultados são gerados para análise.

\section{Resultados e discussão}

Em relação ao modelo desenvolvido e as variáveis apresentadas, estas proporcionam diversas interpretações, que foram analisadas de acordo com o objetivo desta tese. Os valores obtidos para as variáveis de taxa de reciclagem, taxa de descarte e a quantidade de óleo disponível para a reciclagem foram estabelecidas de acordo com dados da UBRABIO (2020).

A inserção de matérias-primas residuais, como o óleo residual de fritura, como fonte alternativa para a cadeia produtiva do biodiesel, pode ser parte importante da futura conjuntura da matriz energética nacional e do aumento e participação da adição de biodiesel ao diesel. Baseado nos dados dos cenários estudados, foi possível verificar que o aumento da participação do óleo de fritura na cadeia de produção de biodiesel apresenta 
benefícios ambientais imensuráveis, visto que quanto mais aumenta a taxa de reciclagem menor será a taxa de descarte deste resíduo, minimizando os impactos ambientais causados pelo descarte incorreto.

Para a realização da simulação, foram projetados dois cenários (sustentável e não sustentável), que foram definidos a partir de um cenário atual. No cenário sustentável, mais otimista, a quantidade de biodiesel utilizada foi incrementada gradativamente, dos atuais $12 \%$, até chegar em $50 \%$ no último ano da simulação, o horizonte de tempo simulado no experimento foi de 10 anos (2020-2030).

A primeira análise desenvolvida com o modelo refere-se a variável consumo doméstico, a partir do óleo utilizado para o consumo residencial menos o óleo descartado, o óleo reciclado e as perdas no processo de fritura, conforme Figura 2.

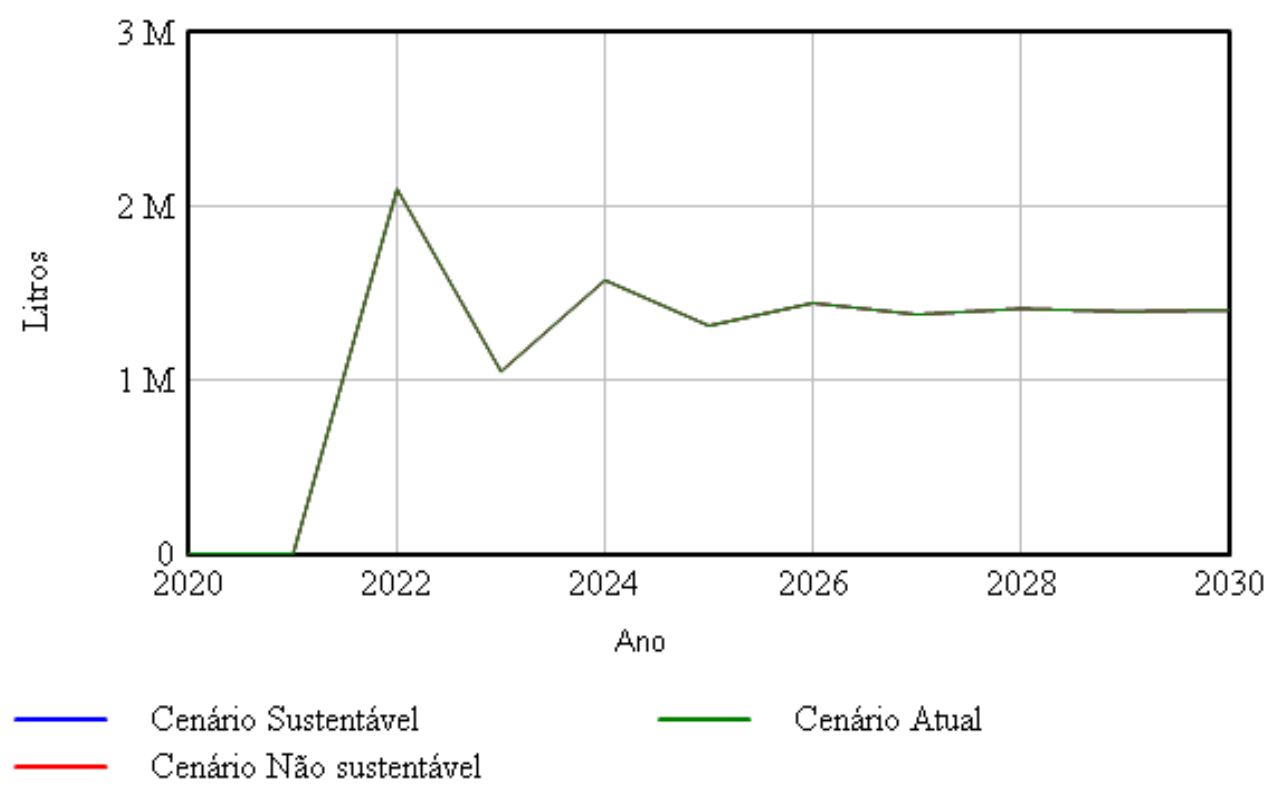

Figura 2. Consumo doméstico. Fonte: Elaborado utilizando o software VENSIM PLE.

De acordo com dados da ABIOVE (2020), o Brasil produziu cerca de $84 \mathrm{mil} \mathrm{m}^{3}$ de biodiesel a partir de óleo residual em 2019, cerca de 1,6\% da produção nacional. Este número pode ser ainda maior, visto que uma parcela deste insumo é utilizada em forma composta (blend), superando a produção de alguns óleos vegetais, como o óleo de algodão. A produção de biodiesel, a partir da recuperação de óleos residuais, deve ser também analisada em um contexto no qual o consumo de óleos refinados em residências vem declinando a cada ano devido à mudança de hábitos alimentares. Desta forma, considerando que os grandes consumidores de óleos de fritura já destinam seu produto para indústria de várias naturezas, a utilização desta matéria-prima representa uma parcela crescente de disponibilidade para a produção de biodiesel.

Foi possível verificar que não houve mudança entre os três cenários analisados em relação ao consumo doméstico, isso aconteceu devido aos valores, que permaneceram os mesmos, nos fluxos de entrada. Contudo, esta variável está diretamente ligada as variáveis descarte e reciclagem, que aumentam e diminuem gradativamente conforme os cenários, tendo um significativo aumento em 2022, quando o percentual de adição do biodiesel ao diesel aumenta para 15\%, refletindo no aumento de óleo residual para reciclagem e um 
platô a partir de 2028, quando os valores de ambos os cenários se estabilizam. Este aumento de biodiesel no diesel acontece conforme a Resolução CNPE no 16/2018, que determina o cronograma da adição (Brasil, 2018). De acordo com a medida, haverá adição de um ponto percentual até alcançar os $15 \%$ em 2023, mas como este aumente tem sofrido algumas alterações, nos cenários analisados essa mudança acontece a partir de 2022.

A segunda análise desenvolvida com o modelo refere-se a variável descarte e é estimada a partir de dados do consumo doméstico e da variável taxa de descarte. Essa taxa foi estabelecida conforme os cenários. No cenário sustentável, essa taxa diminui de forma gradativa, assim como ela aumenta no cenário mais pessimista. Enquanto que no cenário atual, as taxas foram mantidas com toda fidelidade aos dados informados. No horizonte de 10 anos simulados, nota-se que o cenário sustentável possui um potencial de redução maior que os outros dois cenários (Figura 3).

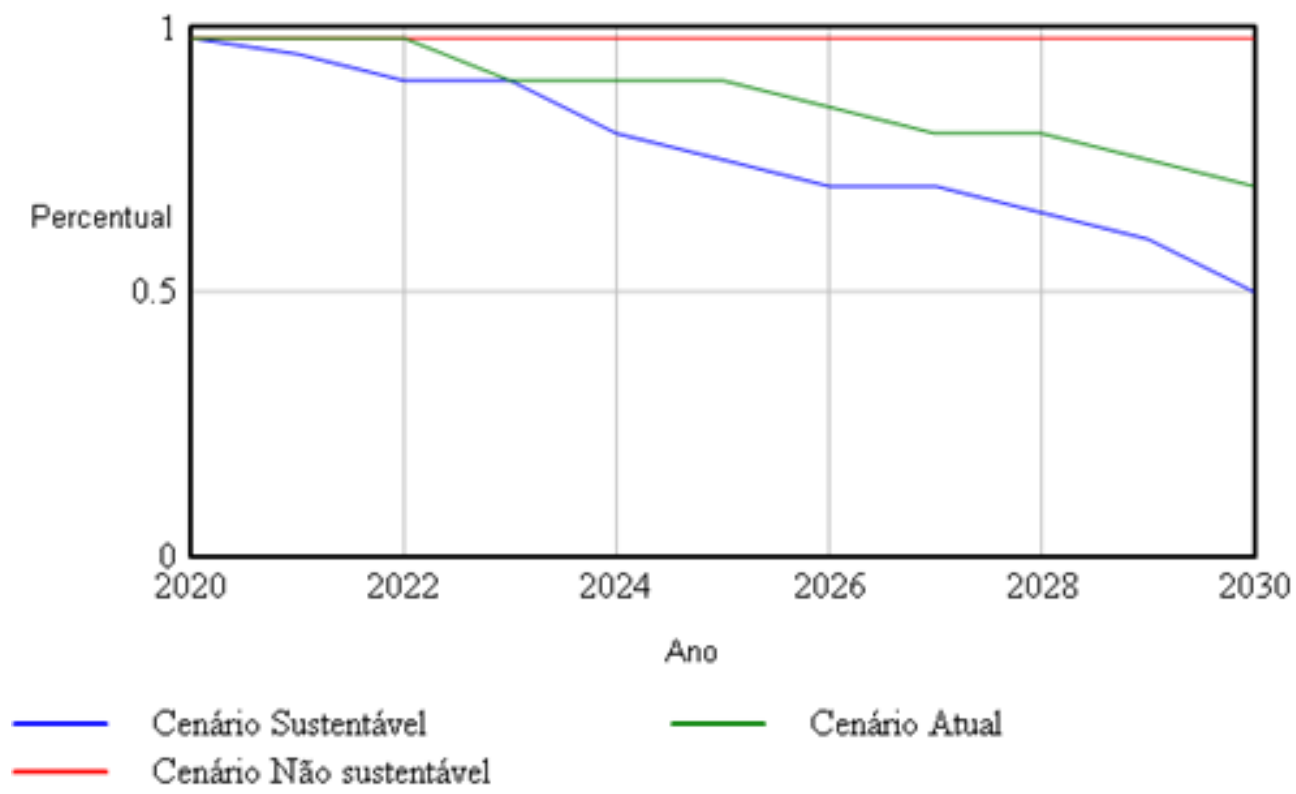

Figura 3. Descarte do óleo residual. Fonte: Elaborado utilizando o software VENSIM PLE.

Na ordenada, é possível verificar a quantidade (litros) de óleo descartado nos três cenários simulados. Os cenários atual e sustentável possuem um ponto em comum no ano de 2023, relacionado com o aumento do percentual de adição do biodiesel ao diesel já previsto por regulamentação e relacionado diretamente com a reciclagem deste insumo. Contudo, o cenário atual apresenta melhorias mais incipientes que o cenário sustentável, que apresenta de forma mais promissora, avanços quanto a reciclagem desta matériaprima, minimizando o descarte deste resíduo no meio ambiente.

O cenário atual ao final do $10^{\circ}$ ano tem uma redução de descarte de 31,5 milhões de litros, enquanto o cenário sustentável apresenta uma redução 52,5 milhões, apresentando uma redução de mais de 21 milhões de litros em relação ao cenário atual.

A variável redução da poluição da água está diretamente ligada à variável descarte, visto que apresenta graficamente a quantidade de água que poderá ser preservada a partir do não descarte do óleo residual de fritura (Figura 4). 
Novamente, o cenário sustentável apresenta um potencial menos poluidor ao meio ambiente quando comparado aos cenários atual e não sustentável. Mantendo-se o cenário atual, no horizonte de 10 anos, este cenário tem o potencial poluidor de mais de 15 trilhões de litros e o cenário não sustentável é capaz de poluir até 20 trilhões de litros de água. É possível perceber que o cenário não sustentável e o atual, tem um maior potencial poluidor que o cenário sustentável, que chega a poluir até 10.500 trilhões litros de água. 0 resultado mostra que ao fim dos 10 anos o cenário sustentável polui $25 \%$ menos, quando comparado com os outros cenários.

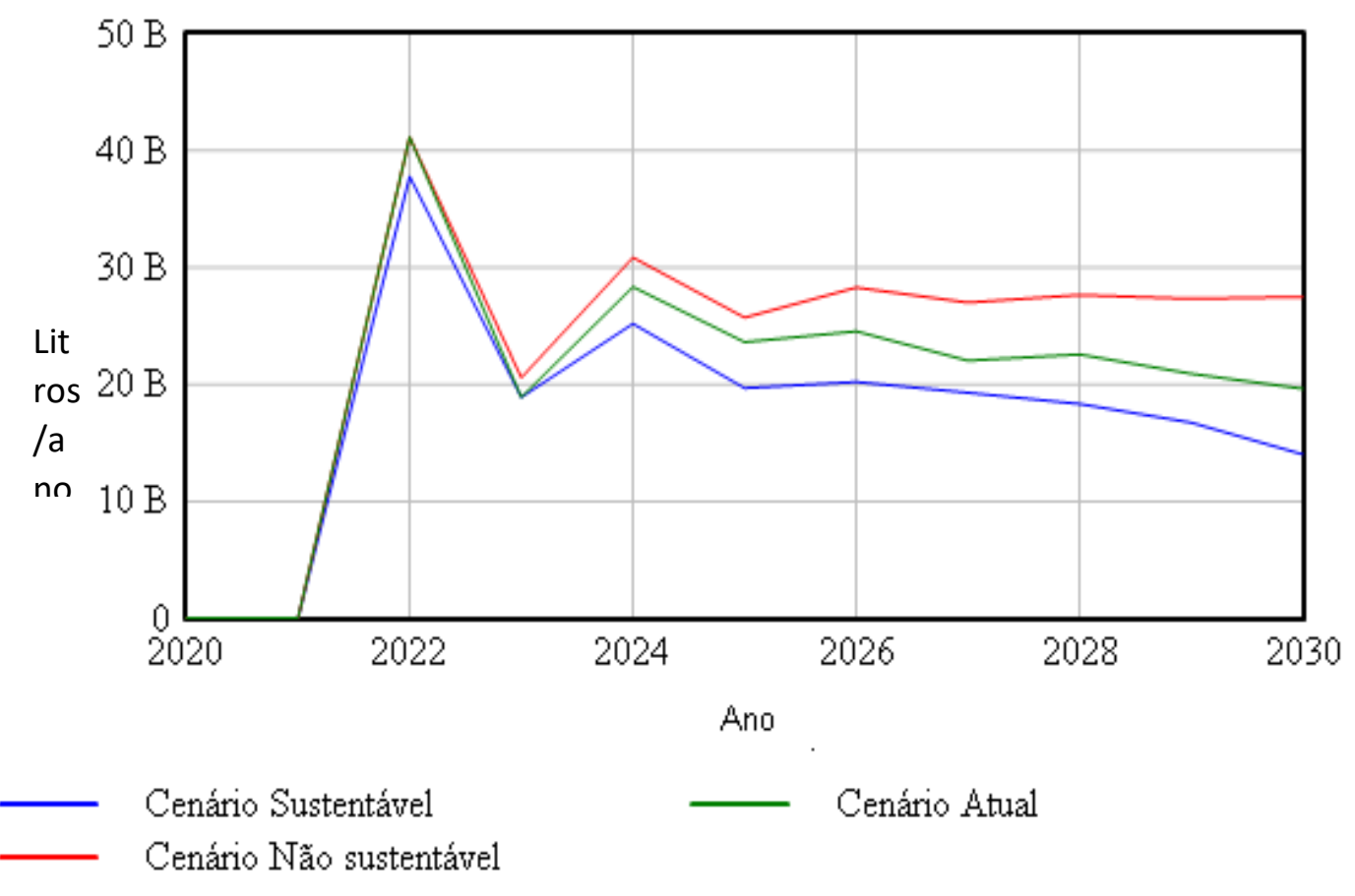

Figura 4. Redução da poluição da água. Fonte: Elaborado utilizando o software VENSIM PLE.

Nos cenários simulados considerou-se que a reciclagem do óleo residual, além de reduzir o impacto ambiental em função do descarte inapropriado, tem outros impactos positivos, como a obtenção de um biocombustível.

O óleo para biodiesel é proporcional ao óleo destinado para reciclagem e a taxa de conversão do óleo em biodiesel pelo percentual destinado a produção de biodiesel, que é influenciado pela variável time, que é modificada para mais ou para menos, conforme o cenário simulado. É possível perceber um aumento do óleo para biodiesel no cenário sustentável, devido ao aumento da quantidade de óleo destino a reciclagem.

Nos cenários modelados considerou-se que a reciclagem do óleo de cozinha, além de minimizar os impactos negativos ao meio ambiente, em função da redução do descarte de forma inadequada, tem outros impactos positivos, como a geração de um combustível menos poluente que os combustíveis fósseis.

O potencial de geração de biodiesel, através da reciclagem, é apresentado na Figura 5, sua variação é diretamente proporcional a quantidade de óleo destinado a produção de biodiesel e a taxa de aproveitamento do processo de reciclagem (óleo/biodiesel). 

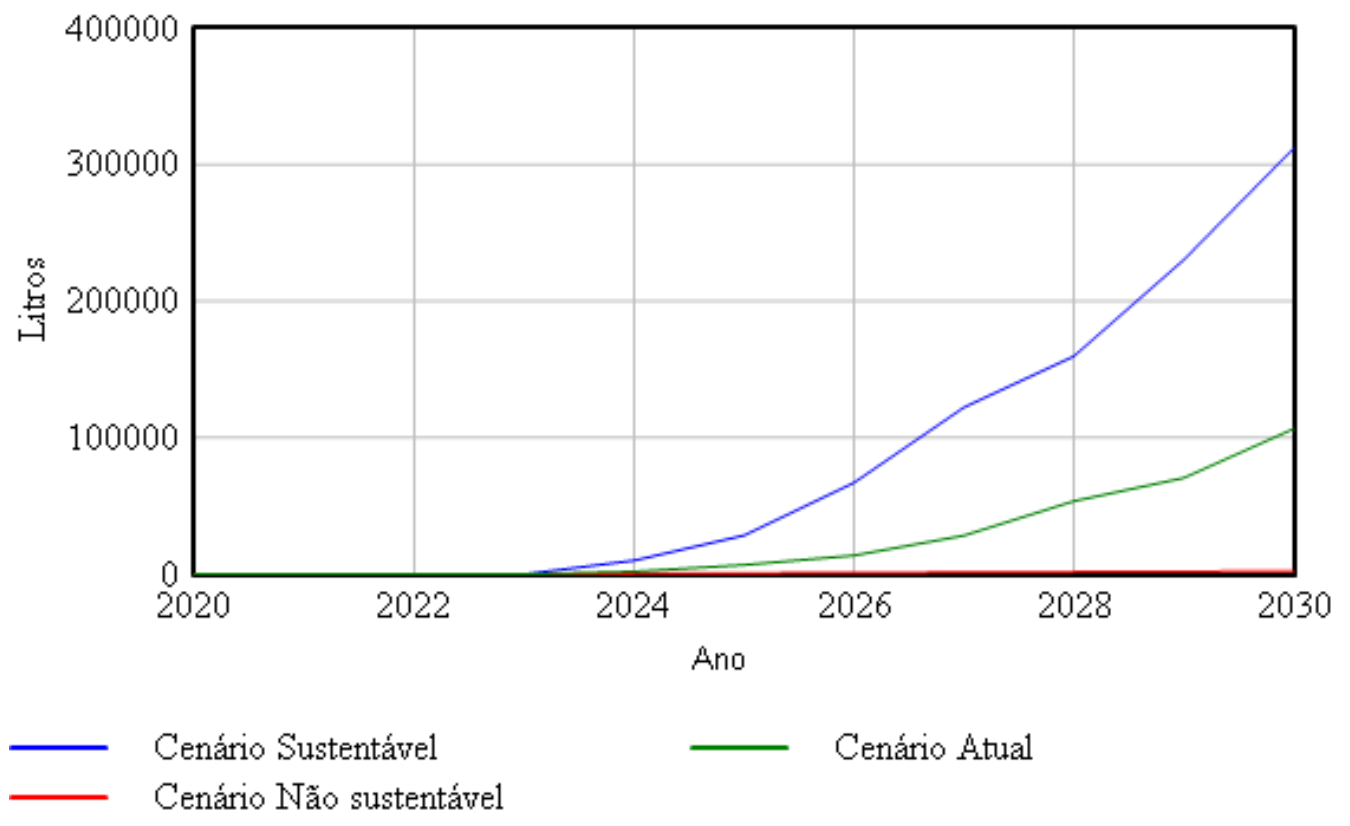

Figura 5. Produção de biodiesel. Fonte: Elaborado utilizando o software VENSIM PLE.

A partir da análise dos cenários simulados, no final do $10^{\circ}$ ano, o cenário sustentável tem um aumento de mais de 160 milhões de litros de biodiesel produzido, sendo superior ao cenário atual que produz cerca de 94 milhões e o cenário pessimista.

No cenário sustentável, em função do crescimento da taxa de aproveitamento do óleo residual em biodiesel, apresenta um resultado $20 \%$ superior aos outros cenários, podendo desta maneira alavancar a produção de biodiesel no Brasil.

0 modelo simulado para a variável $\mathrm{BX}$ representa o somatório das variáveis biodiesel para mistura e taxa de diesel para mistura, menos as emissões. A taxa de diesel para mistura é definida pela variável diesel para mistura, que também é influenciada pela variável time, de acordo com o cenário simulado, e pela variável diesel, que é definida pela quantidade de diesel disponível.

Outra análise realizada se refere ao impacto ambiental causado pelas emissões utilizando o B12 (12\% de biodiesel e $88 \%$ de diesel) até chegar em misturas com maiores teores de biodiesel. Novamente, o cenário sustentável apresenta um potencial de menor poluidor quando comparado com os outros cenários. Na simulação de 10 anos, o cenário sustentável apresenta uma redução significativa na geração de $\mathrm{CO}_{2}$, conforme Figura 6.

Na simulação dos cenários, ao final do horizonte de 10 anos, o cenário atual que chega até o $\mathrm{B} 25$ emite $2,56 \mathrm{~kg} / \mathrm{L}$ de $\mathrm{CO}_{2}$, enquanto o cenário sustentável que chega até $\mathrm{B} 50$ apresenta uma emissão de aproximadamente $2,51 \mathrm{~kg} / \mathrm{L}$ de $\mathrm{CO}_{2}$, podendo ser capaz de reduzir em até $3,30 \%$ a geração de $\mathrm{CO}_{2}$ no ano 10 , reduzindo $1,65 \%$ a mais quando comparando a capacidade de redução de $\mathrm{CO}_{2}$ do Cenário Atual no ano 10. Enquanto que o cenário não sustentável emite $2,58 \mathrm{~kg} / \mathrm{L}$, com redução das emissões em $0,79 \%$.

É possível perceber que o cenário sustentável apresenta melhorias significativas quanto a poluição dos recursos hídricos, redução do descarte do óleo e redução nas emissões de $\mathrm{CO}_{2}$, além do aumento na produção de biodiesel. 


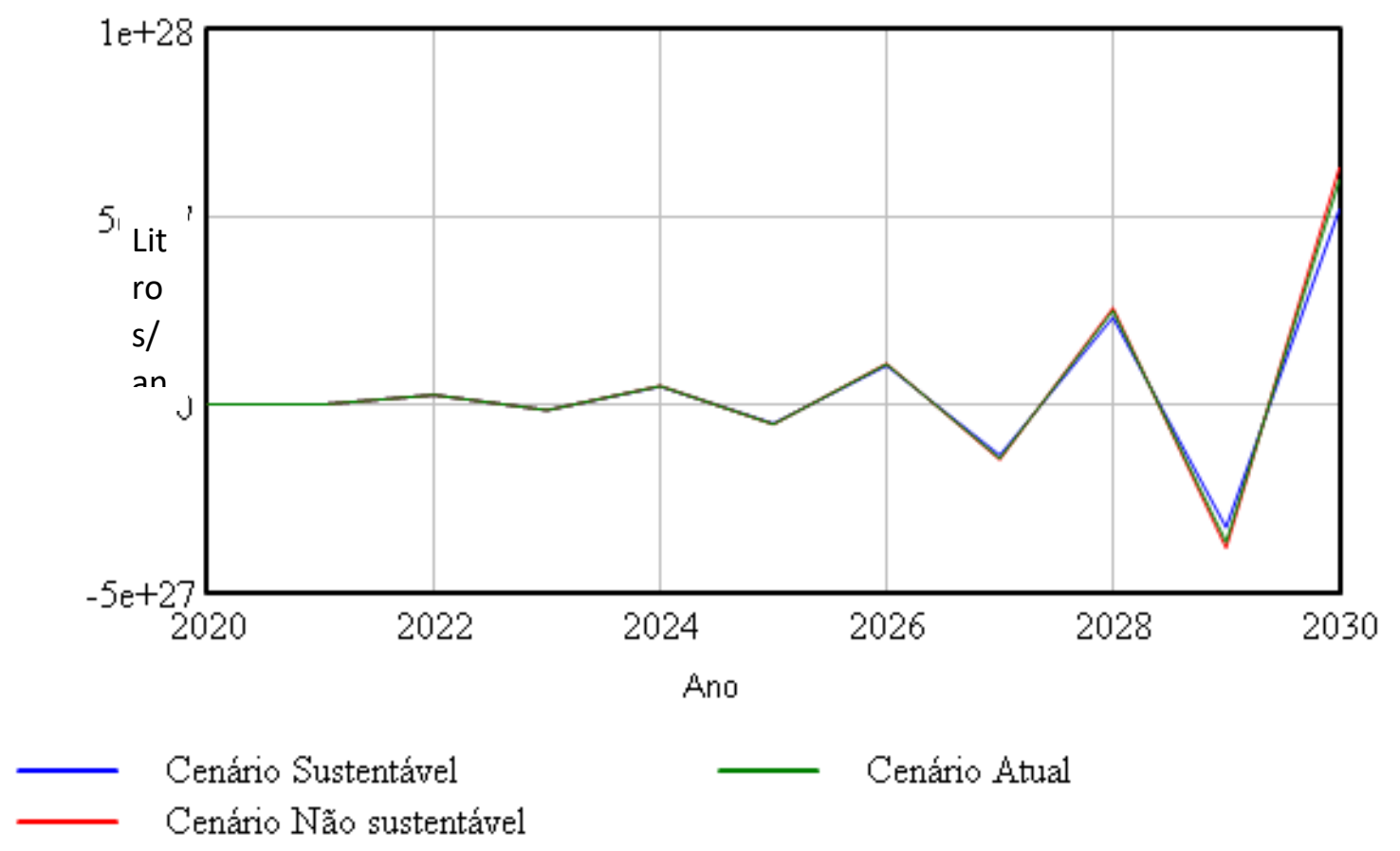

Figura 6. Emissões de $\mathrm{CO}_{2}$. Fonte: Elaborado utilizando o software VENSIM PLE.

Os valores de descarte estão diretamente ligados aos valores de redução da poluição da água, onde do total de óleo que foi para o processo de fritura $(1.050 .000 .000$ L), cada litro pode contaminar até 20.000 L de água. Desta forma, conforme os cenários, esta contaminação pode aumentar ou diminuir. Assim, como a produção de biodiesel está diretamente ligada ao percentual de óleo que é destinado para a produção de biodiesel.

\section{Considerações finais}

Por meio dos resultados obtidos pela análise dos cenários, foi possível verificar que o aumento da participação do óleo residual de fritura na produção do biodiesel representa a garantia de atender as necessidades de abastecimento, com o aumento da produção deste biocombustível. Vale ressaltar que essas iniciativas e ações não abordam somente o reuso ou reciclagem de resíduos, mas também contempla o modo de repensar todo o processo produtivo de modo a minimizar os descartes e aumentar a eficiência do uso em recursos e energia.

Dentre os principais resultados obtidos pela diminuição do descarte e um maior aproveitamento do óleo residual, ao longo de 10 anos, está a produção de biodiesel, que aumentou em mais de 260 milhões de litros. Quanto à redução dos impactos ambientais, também objeto de estudo desta pesquisa, verificou-se que com a reciclagem do óleo residual, a emissão de $\mathrm{CO}_{2}$ no meio ambiente reduz em até $3,30 \%$ em um cenário sustentável, enquanto que no cenário atual reduz em até $1,65 \%$ e no cenário não sustentável reduz em até $0,79 \%$.

A vantagem do óleo residual de fritura poder ser convertido em um biocombustível consiste na produção do biodiesel dentro de um sistema integrado que pode ser uma alternativa quanto ao descarte deste resíduo, bem como servir como insumo produtivo, representando uma diminuição do atual consumo de diesel. Outrossim, é 
necessário considerar a dinamização da economia decorrente de duas fontes: a redução das importações de combustíveis fósseis e o potencial de receita proveniente da comercialização das emissões evitadas de gases do efeito estufa.

\section{Conflito de interesses}

As autoras declaram não haver conflito de interesses.

\section{Referências}

ABIOVE - Associação Brasileira das Indústrias de óleos Vegetais. 2020. Disponível em: $<$ http://abiove.com.br>. Acesso em: 07 set. 2020.

Ahmad, A. L.; Mat Yasin, N. H.; Derek, C. C. J.; Lim, J. K. Microalgae as a sustainable energy source for biodiesel production: A review. Renewable and Sustainable Energy Reviews, v. 15, n. 1, p. 584-593, 2011. https://doi.org/10.1016/j.rser.2012.01.003

ANP - Agência Nacional de Petróleo, Gás Natural e Biocombustível. 2020. Disponível em: <http://www.anp.gov.br/>. Acesso em: 27 fev. 2021.

APROBIO - Associação dos Produtores de Biocombustíveis do Brasil. 2020. Disponível em: <http://www.aprobio.gov.br>. Acesso em: 25 nov. 2020.

Atabani, A. E.; Silitonga, A. S.; Badruddin, I. A.; Mahlia, T. M. I.; Masjuki, T. T.; Mekhilef, T. A comprehensive review on biodiesel as an alternative energy resource and its characteristics. Renewable and Sustainable Energy Reviews, v. 16, n. 4, p. 2070-2093, 2012. https://doi.org/10.1016/j.rser.2012.01.003

Aversari, M.; Nascimento, B. L. A.; Martins, N. C.; Lucena, R. F. P.; Bonifácio, K. M. Cultivo de microalgas em meio alternativo e de baixo custo, enriquecido com resíduos de compostagem: uma proposta para melhoria de vida dos pescadores da Paraíba. Revista Brasileira de Gestão Ambiental e Sustentabilidade, v. 5, n. 11, p. 969-985, 2018. https://doi.org/10.21438/rbgas.051113

Barbosa, G. N.; Pasqualetto, A. Aproveitamento do óleo residual de fritura na produção de biodiesel. Goiânia: Universidade Católica de Goiás, 2007.

Bizawu, K; Aguiar, P. L. M. Energias renováveis e desenvolvimento sustentável: desafios e perspectivas para os países emergentes. Conpedi Law Review, v. 2, n. 4, p. 394-41, 2016. https://doi.org/10.26668/2448-3931_conpedilawreview/2016.v2i4.3671

Brasil. Resolução CNPE no 16, de 29 de outubro de 2018. Dispõe sobre a evolução da adição obrigatória de biodiesel ao óleo diesel vendido ao consumidor final, em qualquer parte do território nacional. Disponível em: <https://www.in.gov.br/materia//asset_publisher/Kujrw0TZC2Mb/content/id/49229059>. Acesso em: 12 dez. 2020.

D’Agosto, M. A. (Coord.). Emissão de gases de efeito estufa - 2050: Implicações econômicas e sociais do cenário de plano governamental. Rio de Janeiro: CENTRO CLIMA/COPPE/UFRJ, 2016. Disponível em: <http://www.centroclima.coppe.ufrj.br/ images/documentos/ies-brasil-2050/3_-_Cenario_de_Emissões_de_GEE_-_Setor_de_ Transportes_Demanda_de_Energia_-_IES_Brasil_2050.pdf>. Acesso em: 12 dez. 2020.

ECOLEO - Associação Brasileira para Sensibilização, Coleta e Reciclagem de Resíduos de Óleo Comestível. 2015. Disponível em: <http://www.ecoleo.org.br>. Acesso em: 23 dez. 2019. 
EMBRAPA - Empresa Brasileira de Pesquisa Agropecuária. 2020. Disponível em: <https://www.embrapa.br/web/portal/soja/cultivos/soja1/dados-economicos>. Acesso em: 21 mar. 2020.

EMF - Ellen MacArthur Foundation. Towards the circular economy: Opportunities for the consumer goods sector. Cowes: Ellen MacArthur Foundation, 2013.

Oliveira, M. M.; Gonçalves, M. F. S. Perspectivas do óleo residual de fritura: uma abordagem econômica, jurídica e socioambiental. Revista Espacios, v. 37, n. 52, p. 17, 2016.

Pauli, R. I. P.; Zajons, B. T.; Schulz, J. R. S.; Freitas, C. A. A segurança alimentar e nutricional (SAN) vem sofrendo restrições pela produção de biocombustíveis? Uma análise a partir do modelo de zockun. Revista de Desenvolvimento Econômico, v. 2, n. 46, p. 210-232, 2020. https://doi.org/10.36810/rde.v2i46.6774

Pereira, P. S.; Veiga, B. V.; Dziedzic, M. Avaliação da influência do fósforo e do nitrogênio no processo de eutrofização de grandes reservatórios. Estudo de caso: Usina Hidrelétrica Foz do Areia. Revista Brasileira de Recursos Hídricos, v. 18, n. 1, p. 43-52, 2013. https://doi.org/10.21168/rbrh.v18n1.p43-52

Santos, R. S. Gerenciamento de resíduos: coleta de óleo comestível. São Paulo: Faculdade de Tecnologia da Zona Leste, 2009.

Sorda, G.; Banse, M.; Kemfert, C. An overview of biofuel policies across the world. Energy Policy, v. 38, n. 11, p. 6977-6988, 2010. https://doi.org/10.1016/j.enpol.2010.06.066

UBRABIO - União Brasileira de Biodiesel e Bioquerosene. 2020. Disponível em: <http://www.ubrabio.com.br>. Acesso em: 20 dez. 2020.

Weetman, C. Economia circular: conceitos e estratégias para fazer negócios de forma mais inteligente, sustentável e lucrativa. São Paulo: Autêntica Business, 2019.

Informação da Licença: Este é um artigo Open Access distribuído sob os termos da Licença Creative Commons Attribution, que permite uso irrestrito, distribuição e reprodução em qualquer meio, desde que a obra original seja devidamente citada. 